\title{
Concomitant Acute Limb Ischemia and Pulmonary Embolism in the Course of SARS-CoV-2 Infection:
}

\section{Case Report}

\author{
Mahassine El Harras ${ }^{* 1}$, Amal Elouarradi ${ }^{1}$, Salma Abdeladim ${ }^{1}$, Fatimazahra Merzouk ${ }^{1}$, Meryem Kassimi ${ }^{2}$, \\ Ilham Bensahi ${ }^{1}$, Sara Oualim ${ }^{1}$, Mohamed Sabry ${ }^{1}$ \\ ${ }^{1}$ Department of Cardiology, Mohammed VI University of Health Sciences Cheick Khalifa Hospital, \\ Casablanca, Morocco \\ ${ }^{2}$ Department of Radiology, Mohammed VI University of Health Sciences Cheick Khalifa Hospital, \\ Casablanca, Morocco
}

*Corresponding author: Mahassine EL HARRAS, Cheick Khalifa International University Hospital, Mohammed VI University of Health Sciences (UM6SS), Mohamed Taieb Naciri avenue, Hay Hassani, ZC: 82403, Casablanca, Morocco; aissamahassine@gmail.com

Received 25 October 2021;

Accepted 14 November 2021;

Published 17 November 2021

\begin{abstract}
Background: The new 2019 coronavirus disease (COVID-19) is associated with significant morbidity and mortality. Thrombotic complications are increasingly recognized as an important part of this disease. Thromboprophylaxis with anti-platelet drugs and anticoagulants are recommended in the initial treatment of the disease. Case presentation: We report the case of a patient hospitalized for a mild form of COVID19 pneumonia, who was admitted, one month later, acute limb ischemia and pulmonary embolism despite antithrombotic prophylaxis. Conclusion: Most reported cases are either arterial or venous thrombosis. The concomitant combination of arterial and venous thrombosis is rarely reported. The prophylactic anticoagulation strategy in the SARS- Cov 2 infection is still not well established.
\end{abstract}

Keywords: Acute limb ischemia, pulmonary embolism, SARS-CoV- 2 infection, thromboprophylaxis.

\section{Introduction}

Since December 2019 the world has been facing a novel severe acute respiratory syndrome caused by coronavirus 2 (SARS-CoV2). It was first spotted in Wuhan, China. On March 2020, COVID19 was declared a pandemic by the World Health Organization ${ }^{[1]}$. Even if the main symptoms are respiratory, systemic complications are more and more diagnosed, and patients present several forms of thromboembolic events, isolated or concomitant as described in our case report.

\section{Case presentation}

A 55 years old woman with type 2 diabetes mellitus and High blood pressure was hospitalized for a mild form of COVID19 pneumonia one month ago. The pneumonia was revealed by radiographic bilateral intrapulmonary opacities consistent with COVID-19. The SARS- CoV-2 infection was subsequently confirmed by reverse transcription PCR, based on a nasopharyngeal swab. No pulmonary thromboembolism was

$\underline{\text { www.ijirms.in }}$ present in the CT imaging. Standard prophylactic regime of low molecular weight heparin was performed as recommended. The patient was discharged on $6^{\text {th }}$ day, she didn't have any chest pain, dyspnea, sign of venous thrombosis nor peripheral vascular disease. The peripheral oxygen saturation was above 95\%. Two weeks later the patient suffered from a cold and painful foot with dyspnea class II of the NYHA. On examination, her heart rate was regular but tachycardic, the room air oxygen saturation was $90 \%$. The findings of heart and chest examinations were unremarkable. Dorsal is pedis and posterior tibial pulses were absent with loss of sensation. We also noted cyanosis and subsequent gangrene to the distal aspect of the involved foot. There were no signs of deep venous thrombosis.

As part of the cardiac assessment a transthoracic electrocardiography was performed. It showed sign of right ventricular dysfunction. CT pulmonary angiography showed bilateral filling defects of the pulmonary artery (Figure 1). Limb Angiography revealed a complete occlusion of the popliteal and posterior tibial (Figure 2). 
Unfractionated heparin was initiated, an endovascular revascularization was performed. An amputation was recommended, the patient was discharged on the 6th day to give
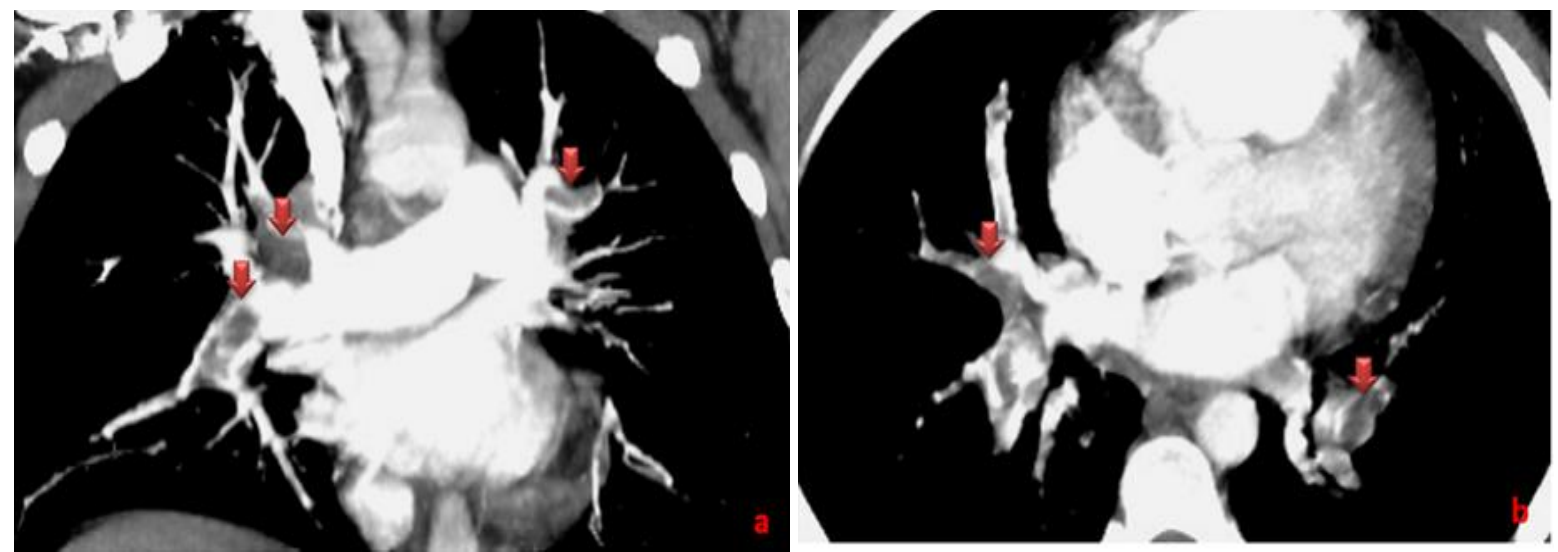

Figure 1: Coronal (a) and Axial (b) CT pulmonary angiographic image showing bilateral filling defects of the pulmonary artery (red arrows).

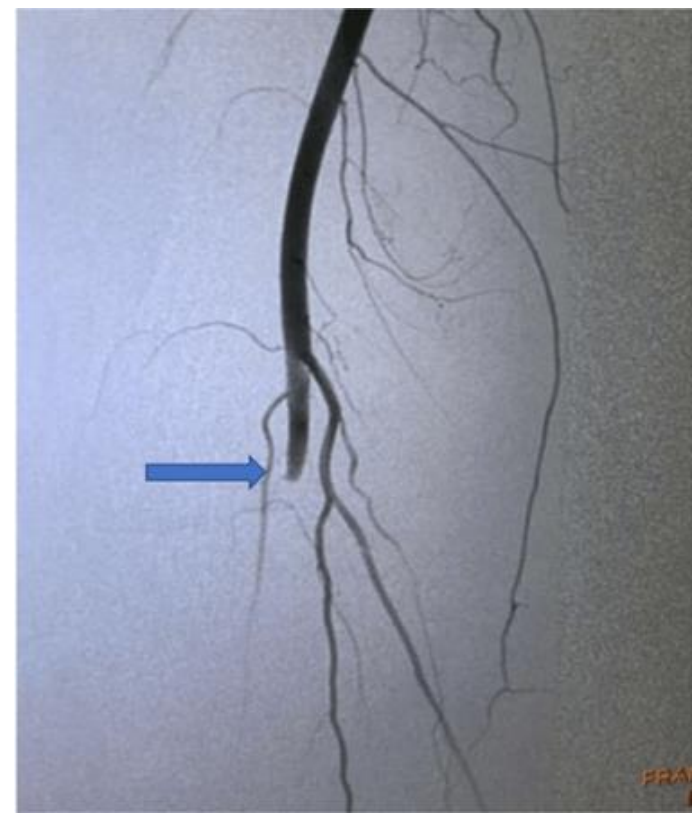

Figure 2: Limb Angiography showing a complete occlusion of the popliteal artery (blue arrow)

\section{Discussion}

The main clinical presentations of SAR-CoV19 include acute chest syndrome with bilateral pneumonia requiring advanced medical support and intensive care ${ }^{[2]}$. The infection can be divided into three phases. Mild infection, the pulmonary phase, and the third phase which is an inflammatory phase leading to the most common complication of COVID-19 ${ }^{[3]}$. SARS-CoV-2 has a high binding affinity for human ACE-2 which broke Angiotensin I. When this peptide hormone is not broken down by ACE-2, it promotes an inflammatory state in the body and causes injury to endothelium ${ }^{[4]}$. The inflammation is creating a hypercoagulable state. Another hypothetical mechanism may be Complement activation in viral pneumonia. Other clinical factors, such as hypoxemia, hyperthermia, and hypovolemia, may also increase the state of hypercoagulation in patients treated for COVID-19.

Several thrombotic complications have been described due to this hyperinflammatory response provoked by the SARS-CoV-2; it leads to various types of ischemic and thrombotic events as described in our case report. Acute limb ischemia manifested by acute limb pain, focal hypothermia, skin mottling, absent pulse, or limb all chances to be salved. Two weeks later the patient underwent a successful trans-metatarsal amputation. 
thrombotic complications were diagnosed in $42 \%$ of patients with COVID-19 ARDS, and pulmonary embolisms in $16.7 \%$ of them. Despite anticoagulation, a high number of patients with COVID-19 ARDS developed life-threatening thrombotic complications, suggesting that anticoagulation targets must be higher than in usual critically ill patients ${ }^{[10]}$. Coagulopathy in SARS-CoV-2 infection is associated with high mortality. The D-dimer and fibrinogen degradation products (FDP) are the most important markers for the coagulopathy. Biomarkers disorders like low levels of platelets, increased levels of D-dimer, and increasing levels of prothrombin in COVID-19, are associated with poor prognosis. These disorders are explained by thromboembolic complications in patients with severe disease ${ }^{[2]}$. D-dimer level was significantly higher in PE group. It supposes that the significant increase of D-dimer in severe novel coronavirus pneumonia patients is a reliable index for identifying high-risk groups of VTE. Even more a higher Ddimers, FDP levels, longer PT and APTT (activated partial thromboplastin time) were found in non-survivors pneumonia patients compared to survivors on admission ${ }^{[7,11,12]}$. The contrastenhanced CT should be used in patients with marked elevation of D-dimer in the course of COVID-19 pneumonia ${ }^{[11]}$.

The prophylactic anticoagulation did not avoid the occurrence of PE in hospitalized patients, and there is a necessity to adapt thromboprophylaxis in patients with SARS-CoV-2 infection. The International Society on Thrombosis and Haemostasis and the American Society of Hematology suggest that all hospitalized COVID-19 patients should receive thromboprophylaxis, or full therapeutic-intensity anticoagulation if such an indication is present. Seriously ill COVID-19 patients should not receive therapeutic-intensity anticoagulation empirically, i.e., in the absence of confirmed venous thromboembolism ${ }^{[13]}$. A more aggressive individualized anticoagulation strategy might be required in selected cases. The crucial question is which patients must be anticoagulated and how?? A Randomized, Open-label Phase 3 Clinical Trial is ongoing to study prevention of COVID-19 associated thrombosis, coagulopathy and mortality with Low- and High-dose anticoagulation with Enoxaparin ${ }^{[3]}$.

\section{Conclusion}

Our patient had both arterial and venous thromboembolic events despite thromboprophylaxis regime. There are some few cases reported in the literature, the incidence of concomitant arterial and venous thrombosis was up $0.5 \%$ in a Spanish study ${ }^{[14]}$. Through this report case we highlighted the possibility to develop thromboembolic events far from hospitalization for mild COVID19 pneumonia. These complications can have a functional and vital prognosis. The high-risk patients, according to biomarkers shown before, must be identified and monitored.

\section{Abbreviations}

SARS-CoV-2: Severe acute respiratory syndrome coronavirus 2

PCR: Polymerase chain reaction

CT: Computed tomography

NYHA: New York Heart Association

ACE: Angiotensin converting enzyme

PE: Pulmonary embolism

VTE: Venous thromboembolism

FDP: Fibrinogen degradation products

PT: Prothrombin time

APTT: Activated partial thromboplastin time

\section{Declarations}

\section{Ethical approval and consent to participate}

Not applicable

\section{Consent for publication}

Written informed consent was obtained from the patient for her anonymized information to be published in this article

\section{Availability for supporting data}

Data requests should be made to the corresponding authors.

\section{Competing interests}

The authors report no conflict of interest.

\section{Funding}

This study did not receive any funding support.

\section{Authors' contributions}

All authors have read and agreed to the final version of this manuscript.

\section{Acknowledgements}

Not applicable

\section{References}

[1] Zhu N, Zhang D, Wang W, et al. A Novel Coronavirus from Patients with Pneumonia in China, 2019. N Engl J Med. 2020;382(8):727-733.

[2] F. Zhou, T. Yu, R. Du, G. Fan, Y. Liu, Z. Liu, et al., Clinical course and risk factors for mortality of adult inpatients with COVID-19 in Wuhan, China: a retrospective cohort study, Lancet. 395 (10229) (2020) 1054-1062.

[3] Magro G. COVID-19: Review on latest available drugs and therapies against SARS-CoV-2. Coagulation and inflammation cross-talking. Virus Res. 2020 Sep;286:198070.

[4] Violi F, Pastori D, Cangemi R, Pignatelli P, Loffredo L. Hypercoagulation and antithrombotic treatment in coronavirus 2019: a new challenge. Thromb Haemostasis. 2020 Jun;120(6):949e956.

[5] Bellosta R, Luzzani L, Natalini G, et al. Acute limb ischemia in patients with COVID-19 pneumonia [published online ahead of print, 2020 Apr 29]. J Vasc Surg. 2020; S0741-5214(20).

[6] Putko RM, Bedrin MD, Clark DM, Piscoya AS, Dunn JC, Nesti LJ. SARS-CoV-2 and limb ischemia: A systematic review. J Clin Orthop Trauma. 2021;12(1):194-199.

[7] Cui S, Chen S, Li X, Liu S, Wang F. Prevalence of venous thromboembolism in patients with severe novel coronavirus pneumonia. J Thromb Haemost. 2020;18(6):1421-1424. 
[8] Menter T, Haslbauer JD, Nienhold R, et al. Postmortem examination of COVID-19 patients reveals diffuse alveolar damage with severe capillary congestion and variegated findings in lungs and other organs suggesting vascular dysfunction. Histopathology. 2020;77(2):198209.

[9] Wichmann D, Sperhake JP, Lütgehetmann M, et al. Autopsy Findings and Venous Thromboembolism in Patients With COVID-19: A Prospective Cohort Study. Ann Intern Med. 2020;173(4):268-277.

[10] Helms J, Tacquard C, Severac F, et al. High risk of thrombosis in patients with severe SARS-CoV-2 infection: a multicenter prospective cohort study. Intensive Care Med. 2020;46(6):1089-1098.

[11] Bompard F, Monnier H, Saab I, et al. Pulmonary embolism in patients with COVID-19 pneumonia. Eur Respir J. 2020;56(1):2001365. Published 2020 Jul 30.

[12] Tang N, Bai H, Chen X, Gong J, Li D, Sun Z. Anticoagulant treatment is associated with decreased mortality in severe coronavirus disease 2019 patients with coagulopathy. J Thromb Haemost. 2020;18(5):1094-1099.

[13] Thachil J, Tang N, Gando S, et al. ISTH interim guidance on recognition and management of coagulopathy in COVID-19. J Thromb Haemost. 2020;18(5):1023-1026.

[14] Muñoz-Rivas, Nuria et al. "Systemic thrombosis in a large cohort of COVID-19 patients despite thromboprophylaxis: A retrospective study.” Thrombosis research, vol. 199 132-142. 7 Jan. 2021, doi:10.1016/j.thromres.2020.12.024.

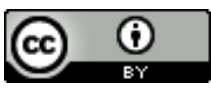

Open Access This article is licensed under a Creative Commons Attribution 4.0 International License, which permits use, sharing, adaptation, distribution and reproduction in any medium or format, as long as you give appropriate credit to the original author(s) and the source, provide a link to the Creative Commons license, and indicate if changes were made. The images or other third party material in this article are included in the article's Creative Commons license, unless indicated otherwise in a credit line to the material. If material is not included in the article's Creative Commons license and your intended use is not permitted by statutory regulation or exceeds the permitted use, you will need to obtain permission directly from the copyright holder. To view a copy of this license, visit https://creativecommons.org/licenses/by/4.0/.

(C) The Author(s) 2021 